Journal of Social Sciences 7 (2): 199-208, 2011

ISSN 1549-3652

(C) 2010 Science Publications

\title{
Banking Efficiency in Lebanon: An Empirical Investigation
}

\author{
Mouataz Zreika and Nasser Elkanj \\ School of Economics and Finance, University of Western Sydney, Australia
}

\begin{abstract}
Problem statement: The main goal behind this study is to identify whether banks are working at full efficiency or not and spot the changes in efficiency for banks operating in Lebanon after 2007 financial crisis. Approach: This study was conducted to examine the technical efficiency of 40 banks operating in Lebanon over the two sub-periods 2002-2006 and 2006-2009 using Data Envelopment Analysis (DEA). Results: The results from DEA show that the extent of technical efficiency varies across the banks. Citibank, HSBC, BBAC, IBL and FBL are found to be working at fully technical efficiency, while RBA, HBA, BCN, SGBL, BLA and SLCB are found to be prominently inefficient. Technical efficiency is the highest in large banks and lowest in small banks. Conclusion: After 2007 financial crisis, foreign banks have suffered more with technical efficiency decreasing in foreign banks, while local banks had a significant increase in technical efficiency. Small and medium banks are found to be working at increasing returns to scale, while large banks are working at decreasing returns to scale.
\end{abstract}

Key words: Data Envelopment Analysis (DEA), Technical Efficiency (TE), Pure Technical Efficiency (PTE), Scale Efficiency (SE), financial crisis, empirical investigation

\section{INTRODUCTION}

The Lebanese banking position is unique in the Middle East with rapid development since the 1990s. During the 2007 financial crisis, the Lebanese banks remained safe and completely unaffected by the crisis; due to Lebanese Reserve Banks' legislations not allowing the banks' executives from investing in highrisk structured products. Moreover, the Lebanese banks have always preserved a comparatively high liquidity in Lebanese Pound (LBP) and in foreign currencies allocated between the domestic and external markets without any concentration in a domestic or a correspondent bank. The liquidity in the sector played a substantial role in safeguarding the banking sector. On the contrary, the financial crisis gave the Lebanese banks a huge push with an increase in deposits by $15.6 \%$, total assets by $14.6 \%$, total loans by $18.64 \%$ and net profits by nearly 30\% in 2008 .

The major objective behind this study is to study the efficiency of banks operating in Lebanon during the period 2002-2009. To start with, we will provide an overview of the Lebanese financial and banking system.

In Lebanon, financial intermediaries are divided into five major types:

- Commercial banks

- Banks specializing in medium and long-term credit

- Money dealers
- Financial institutions (regarded as investment banking firms)

- Brokerage firms

Besides these financial intermediaries, a number of foreign banks have representative offices in Lebanon. The most important group we are interested in this study is commercial banks. By the end of 2008, there were 67 banks working in Lebanon, out of which 55 commercial banks and 12 investment banks (Table 1). Out of the 55 banks there were 11 branches for foreign and Arab banks only. There were 18,632 employers working in banks as follows: 17,531 in commercial banks and 323 in Arab banks, 425 in foreign banks and 353 in investment banks.

As for money dealers, they are mainly small retail foreign-exchange dealers who do not supply loans or accept deposits. On the other hand, investment banks are small sized firms that help businesses getting long term finance and as well trade securities on behalf of customers. Finally, there are brokerage firms that do not underwrite securities but trade securities on behalf of customers.

The Lebanese banking system has four main characteristics:

- The banking secrecy law: Under the Lebanese law, there is no law that can force banks to reveal a client's identity. The only possible cases at which secrecy is revealed is when the client goes bankrupt, or he gives a written consent, or he dies 
J. Social Sci., 7 (2): 199-208, 2011

Table 1: Lebanese banking and financial structure

\begin{tabular}{|c|c|c|c|c|c|c|c|c|}
\hline & 2001 & 2002 & 2003 & 2004 & 2005 & 2006 & 2007 & 2008 \\
\hline \multicolumn{9}{|l|}{ Commercial banks } \\
\hline Total number & 60 & 53 & 52 & 53 & 54 & 54 & 54 & 55 \\
\hline $\mathrm{o} / \mathrm{w}$ foreign banks & 14 & 11 & 10 & 10 & 10 & 10 & 10 & 11 \\
\hline Number branches & 780 & 787 & 809 & 799 & 825 & 830 & 847 & 855 \\
\hline $\mathrm{o} / \mathrm{w}$ foreign banks & 48 & 41 & 40 & 38 & 38 & 34 & 34 & 35 \\
\hline \multicolumn{9}{|l|}{ Investment banks } \\
\hline Total number & 8 & 8 & 9 & 10 & 10 & 9 & 1212 & \\
\hline Number of branches & 10 & 10 & 11 & 12 & 12 & 14 & 17 & 17 \\
\hline \multicolumn{9}{|l|}{ Financial institutions } \\
\hline Total number & 28 & 26 & 28 & 29 & 33 & 38 & 43 & 45 \\
\hline Number of branches & 32 & 30 & 32 & 33 & 37 & 43 & 48 & 50 \\
\hline \multicolumn{9}{|c|}{ Financial intermediaries } \\
\hline Total number & 5 & 5 & 7 & 9 & 9 & 9 & 10 & 11 \\
\hline \multicolumn{9}{|l|}{ Leasing companies } \\
\hline Total number & 3 & 3 & 3 & 3 & 3 & 3 & 2 & 2 \\
\hline
\end{tabular}

Source: Banque du Liban. (Lebanon Reserve Bank)

Table 1: Total assets, total deposits and total loans

\begin{tabular}{llllllll}
\multicolumn{1}{l}{ Table 1: Total assets, total deposits and total loans } \\
\hline & 2003 & 2004 & 2005 & 2006 & 2007 & 2008 & 2009 \\
\hline Total assets & 60.115 & 67.786 & 68.538 & 74.27 & 82.255 & 94.255 & 115.25 \\
Yearly change & $14.37 \%$ & $12.76 \% \mathrm{a}$ & $1.11 \%$ & $8.36 \%$ & $10.75 \%$ & $14.59 \%$ & $22.27 \%$ \\
Total deposits & 40.989 & 45.286 & 47.517 & 51.321 & 57.699 & 66.274 & 79.193 \\
Yearly change & $12.21 \%$ & $10.48 \%$ & $4.93 \%$ & $8.00 \%$ & $12.43 \%$ & $14.86 \%$ & $19.49 \%$ \\
Customer loans & 15.148 & 15.934 & 14.46 & 15.32 & 17.752 & 21.062 & 24.259 \\
Y14e-arly change & $-0.39 \%$ & $5.19 \%$ & $-9.25 \%$ & $5.93 \%$ & $15.90 \%$ & $18.64 \%$ & $15.18 \%$ \\
\hline
\end{tabular}

Source: Banque du liban

- Free exchange system and free movement of capital and earnings: The Lebanese exchange system has no restrictions on currency exchanging from Lebanese currency to any other currency. Also, there are no borders placed on the free flow of capital and earnings inside or outside the country. On the other hand, the law allows for mutual communication between banks for information related to the client, in order to guarantee the security of banks' investments

- Tax exemptions: Any account opened in Lebanese banks is exempted from income tax on all interest and revenues earned

- Free banking zone: The Lebanese government exempted non residents' deposits and liabilities in foreign currency from paying the income tax on interest earned

The Lebanese banks play a core role in financing the Lebanese economy, a positive role for stabilizing the monetary policy and for the development of payment systems. To large extent, banks operating in Lebanon stayed unaffected from the 2007 financial crisis. Neither the government, nor the Lebanese Reserve Bank interfered by adding any additional liquidity or changing the interest rates. On the other hand, deposits, profits and lending activities increased continuously since 2003. Most banks in advanced countries depend on credit or financial markets as a main source of funds and not like Lebanese banks which depend on deposits.

The Lebanese banking sector has achieved a period of healthy activity after the 2007 financial crisis with an unprecedented growth in lending activity (Table 2). Total loans have increased by $58.35 \%$ from 15.32 US billion dollars in 2006-24.259 US billion dollars in 2009. This means that banks have been able to supply the growing lending needs of the economy when banks around the world have witnessed subdued lending activity within the context of a slow recovery and continuing deleveraging across the board. Total assets have increased by $55.17 \%$ between 2006 and 2009 . Furthermore, total deposits of banks operating in Lebanon rose by $54.31 \%$ over the same period, moving from 51.321 US billion dollars to 79.196 US billion dollars. The share of non-resident deposits in total deposits has reached a record high of $28.2 \%$ by end of 2009 due to the large amount of inflows into the country in the aftermath of the financial crisis. This shows clearly that the financial structure of banks operating in Lebanon have strengthened during 20062009 due to the positive effect on total assets, total deposits and customer loans.

Previous studies on efficiency: There have been a large number of international studies in the area of bank 


\section{J. Social Sci., 7 (2): 199-208, 2011}

efficiency during the last half century in the United States and European countries. One of the first studies using DEA was Sherman and Gold (1985) who analyzed banks efficiency in 14 US banks and looked at the relative efficiency of branches for a saving bank in the United States (Sherman and Gold, 1985). Three inputs and one output were employed. The inputs are employees, expenses and space. The outputs included number of transactions only. Also using DEA, there was an early study by Parkan (1987) on 35 branches of a major commercial bank in Canada with four inputs and three outputs (Parkan, 1987). The inputs were expenses, space, rent, number of employees and terminals, while the outputs were number of transactions and customer responses. Other studies included Vassiloglou and Giokas (1990) and Giokas (1991) on Greek banks, Favero and Papi (1995) on Italian banks, Sherman and Ladino (1995) on US banks, Athanassopoulos and Curram (1996) on UK banks, Resti (1997) on Italian banks, Schaffnit et al. (1997) Canadian banks, Golany and Storbeck (1999) on US banks, Seiford and Zhu (1999) on US banks and Wu et al. (2006) on Canadian banks.

However, more recent studies have focused on Banks in the Middle East area. One of the first attempts to study the efficiency in the area was a study by Oral and Yolalan (1990), who assessed the efficiency in 20 branches of a Turkish commercial bank (Oral and Yolalan, 1990). Another study by AlFaraj et al. (1993) have focused on the relative efficiency of 15 bank branches of one of the biggest banks in Saudi Arabia using one year data with eight inputs and seven outputs (Al-Faraj et al., 1993). AlShammari and Salimi (1998) examined the efficiency of Jordanian banks over the period 1991-1994 and found that the majority of Jordanian banks are fairly not efficient Al-Shammari and Salimi (1998). Another study by Hassan et al. (2004) evaluated the efficiency for 31 banks operating in Bahrain for the period 19982000 and found that all banks have improved their efficiency levels (Hassan et al., 2004). Mostafa (2007) examined the efficiency for 85 Arab banks using DEA. He used assets and equity as inputs and net profits, Rate On Assets (ROA) and Rate On Equity (ROE) as outputs. He concluded that Banque de Cairo (Egypt), National Bank of UAQ (UAE), United Arab Bank (UAE) and Egyptian American Bank (Egypt) were the most efficient banks. Emrouznejad and Anouze (2009) have used the same outputs and inputs as in Mostafa (2007) and reported that the results in Mostafa (2007) were incorrect.
In contrast, there are very little empirical studies focusing on Lebanese banks. In fact, the most recent three studies on Lebanese banks efficiency are by Saad and Moussawi (2008; 2009). Saad and Moussawi (2009) have assessed the efficiency of 43 Lebanese Commercial banks over the period 1992-2005 using Data Envelopment Analysis and Stochastic Frontier Analysis. There results showed that efficiency for commercial banks has increased from $73.96 \%$ in $1992-$ $84.02 \%$ in 2005 when using DEA method and from 73.96-84.02\% when using the stochastic frontier. The second study by Saad and Moussawi (2008) compared the efficiency of domestic banks versus foreign banks operating in the Lebanon between 1996 and 2005. There results showed that the banks with majority foreign ownership increased efficiency when compared to domestic banks that recorded decrease in efficiency. Another study has measured the relative efficiency of Lebanese banks between 1997 and 2004 using DEA method. The study has reached a conclusion that smaller banks tends to transform their inputs into outputs more effectively than larger banks.

Measures of bank efficiency: Farrell (1957) launched the start of measuring efficiency through his study: "the measurement of productive efficiency" following the ideas of Farrell (1957) and Debreu (1951). In his study, he claimed that efficiency of a firm consists of Technical Efficiency (TE) and Allocative Efficiency (AE). Technical efficiency measures the ability of a firm to maximize output from a certain amount of inputs; while allocative efficiency measures the ability of a firm to utilize its inputs in the best possible mixture, given their own prices and production technology. Technical efficiency can be split into Scale Efficiency (SE) and Pure Technical Efficiency (PTE). Scale efficiency is the possible gain from attaining optimal size of a firm which reflects the Most Productive Scale Size (MPSS); whereas the pure technical efficiency measure the effectiveness of the management in implementing effective production plans for converting inputs to outputs. Combining allocative efficiency with technical efficiency gives a measure of Overall Efficiency (OE).

Measures of allocative and technical efficiencies: To understand the difference between allocative and technical efficiency, we are going to use the same simple and diagrammatic example used by Farrell (1957). Farrell assumed that a firm uses two inputs ( $\mathrm{x}_{1}$ and $x_{2}$ ) for the production of one output (y) under the assumption of Constant Return Scale (CRS) (Fig. 1). 


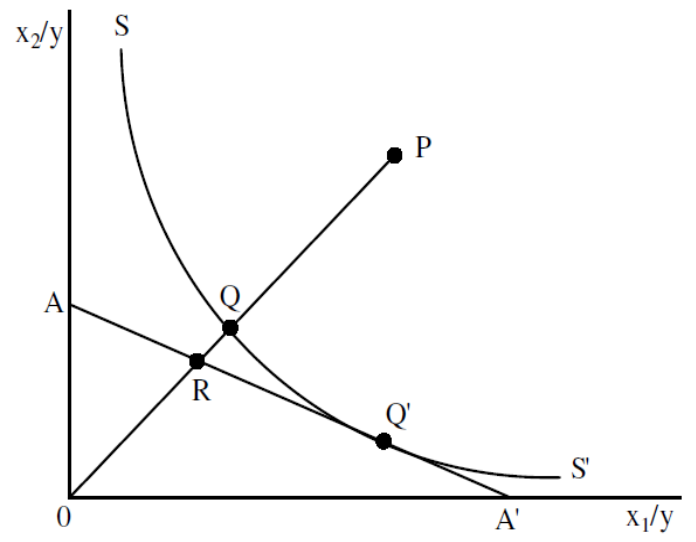

Fig. 1: Technical and allocative efficiency. Source: Coelli et al. (1998)

The curve SS' represents the unit isoquant of fully efficient firms, which allows the measurement of technical efficiency. If a firm is operating on the curve that means the firm is supposed to be technically efficient such as at the point Q. If a firm is operating at point $P$, then this firm is said to be technically inefficient by the distance between point $\mathrm{Q}$ and point $\mathrm{P}$; which is the quantity of inputs that can be reduced without a decrease in output levels (QP/OP). Based on that, technical efficiency can be measured by:

$$
\mathrm{TE}_{\mathrm{i}}=\mathrm{OQ} / \mathrm{OP}=1-\mathrm{QP} / \mathrm{OP}
$$

Technical efficiency will have a value between zero and one. A fully efficient firm indicates that technical efficiency is one; whereas zero indicates that the firm is fully technically inefficient.

If the input price ratio can be measured by the slope of AA' line in Fig. 1, then the allocative efficiency of a firm operating at point $\mathrm{P}$ can be measured as:

$$
\mathrm{AE}_{\mathrm{i}}=\mathrm{OR} / \mathrm{OQ}
$$

This means at point $\mathrm{Q}$, the firm will be technically efficient but allocatively inefficient. In order to be allocatively efficient, the production cost should decrease by the distance $\mathrm{RQ}$, so the production take place at the technically and allocatively efficient point Q'. Technical efficiency and allocative efficiency will give overall efficiency which is measured by:

$\mathrm{OE}_{\mathrm{i}}=\mathrm{OR} / \mathrm{OP}$

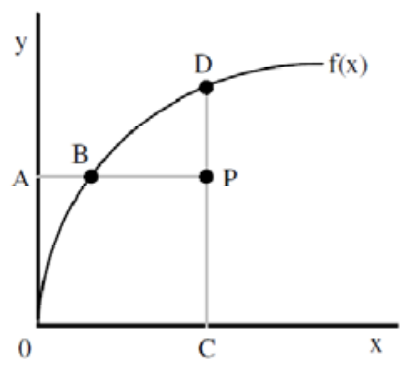

Fig. 2: Decreasing Return to Scale (DRS). Source: Coelli et al. (1998)

Hence, overall efficiency is the product of technical efficiency and allocative efficiency:

$\mathrm{TE}_{\mathrm{i}} \times \mathrm{AE}_{\mathrm{i}}=(\mathrm{OQ} / \mathrm{OP}) \times(\mathrm{OR} / \mathrm{OQ}) \equiv(\mathrm{OR} / \mathrm{OP})=\mathrm{OE}_{\mathrm{i}}$

Overall efficiency, technical efficiency and allocative efficiency are restricted to numbers between one and Zero. When measuring the three kind of efficiencies, the subscript "i" $\mathrm{p}$ ' is used to indicate that it is an input-oriented or input-minimizing measure. An input minimizing measure concentrates on how much would be the reduction in input quantity with no change in the output level produced. Whereas, an outputmaximizing measure focuses on how much output level can be increased with no reduction in the input levels used. To explain the difference between outputmaximizing and input-minimizing measures, a simple example can be taken where a firm has one input and one output as provided by Coelli et al. (1998). Figure 2 represents a Decrease in Returns to Scale (DRS) technology represented by $\mathrm{f}(\mathrm{x})$ and an inefficient firm operating at point $\mathrm{P}$. The input-minimizing measure of technical efficiency would be equal to AB/AP, whilst the output-maximizing measure of technical efficiency would be equal to $\mathrm{CP} / \mathrm{CD}$.

The only case, at which the technical efficiency would be the equal in both cases the output-maximizing and the input-minimizing, is when there is a constant return to scale case (Fare and Lovell, 1978). This can be shown in Fig. 3 where it can be noticed that $\mathrm{AB} / \mathrm{AP}=\mathrm{CP} / \mathrm{CD}$ for the inefficient firm operating at point $P$.

The efficiency from before is measured under Constant Returns to Scale technology (CRS). If Variable Return to Scale technology (VRS) is endorsed, then scale efficiency can be calculated. Figure 4, explains CRS and VRS cases for a firm that have uses one input (x) for the production of output (y). For CRS, technical efficiency at point $\mathrm{P}$ is $\mathrm{PP}_{c}$; while technical 


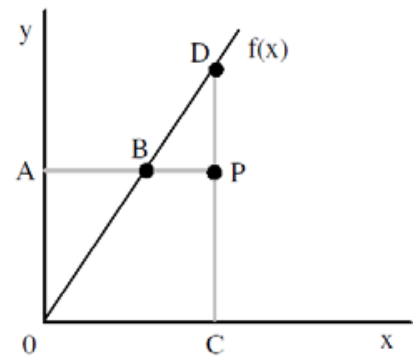

Fig. 3: Constant Returns to Scale (CRS). Source: Coelli et al. (1998)

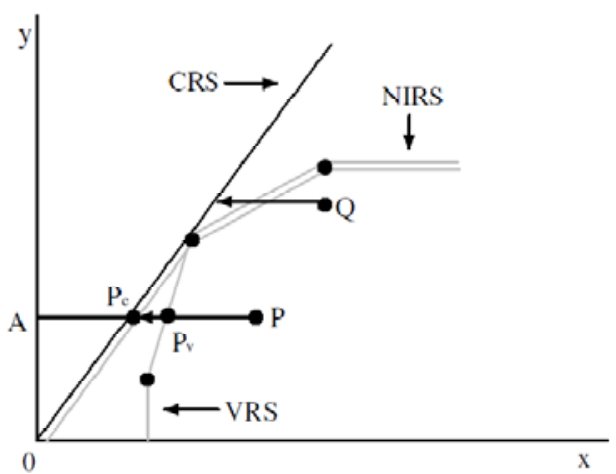

Fig. 4: Scale efficiency. Source: Coelli et al. (1998). Note: CRS denotes Constant Returns to Scale, NIRS Non-Increasing Returns to Scale and VRS Variable Returns to Scale

efficiency is the distance $\mathrm{PP}_{\mathrm{v}}$ under the VRS. The difference between CRS technical efficiency and VRS technical efficiency would be the distance $\mathrm{P}_{\mathrm{C}} \mathrm{P}_{\mathrm{v}}$ which is put down to scale inefficiency. Using efficiency ratios, the same concept can be measured as follows:

$$
\begin{aligned}
& \mathrm{TE}_{\mathrm{CRS}}=\mathrm{AP}_{\mathrm{C}} / \mathrm{AP} \\
& \mathrm{TE}_{\mathrm{VRS}}=\mathrm{AP}_{\mathrm{V}} / \mathrm{AP} \\
& \mathrm{SE}=\mathrm{AP}_{\mathrm{C}} / \mathrm{AP}_{\mathrm{V}}
\end{aligned}
$$

And due to:

$$
\mathrm{AP}_{\mathrm{C}} / \mathrm{AP}=\left(\mathrm{AP}_{\mathrm{V}} / \mathrm{AP}\right) \times\left(\mathrm{AP}_{\mathrm{C}} / \mathrm{AP}\right)
$$

This implies:

$$
\mathrm{TE}_{\mathrm{CRS}}=\mathrm{TE}_{\mathrm{VRS}} \times \mathrm{SE}
$$

$\mathrm{TE}_{\mathrm{VRS}}$ is the pure technical efficiency measure, this means that:
$\mathrm{TE}=\mathrm{PTE} \times \mathrm{SE}$

That is to say, the CRS technical efficiency measure is put up from pure technical efficiency (VRS) and scale efficiency.

Estimating bank efficiency using DEA: For estimating bank efficiency, there are two methods: parametric and non-parametric methods. The parametric methods use statistical methods while the non-parametric methods use mathematical linear programs. Perhaps one of the greatest advantages of any form of non-parametric analysis as compared to parametric analysis is that a parametric approach requires the imposition of a specific functional form-as examples linear regression, non-linear regression, production function. Furthermore, the choice of functional form often requires the assumption of independently and identically normally distributed error terms. Data envelopment analysis does not require any assumptions regarding functional form as DEA calculates a maximal performance measure for each bank relative to all other banks contained within the study. However, it is important to note that the efficiencies measures produced by DEA are a relative measure not an absolute one. This in turn means that the resulting measures are truly empirical and sensitive to the number of banks included. In this study, DEA will be applied to calculate technical efficiency, pure technical efficiency and scale efficiency.

\section{MATERIALS AND METHODS}

The main purpose of this study is to measure the efficiency of the financial system of several Lebanese banks using the DEA that involves the use of linear programming methods to construct a non-parametric surface over the given data set. The main benefit from DEA is optimizing each bank's observation with the objective of extrapolating a discrete piecewise frontier determined by the set of Pareto-efficient Decision Making Units (DMU's). When using traditional parametric methods, one assumes that the optimized regression applies to each decision-making unit, while DEA on the other hand optimizes the measure of performance for each individual decision making unit. The advantage of this approach is that the analyst is able to reveal greater understanding of each DMU instead of 'the depiction of a mythical average DMU'.

The estimation of technical efficiency based on DEA requires data on bank inputs and outputs. In the literature, there are two different approaches. First approach is called 'the intermediation approach' which 
views banks as intermediaries that transfer financial assets from surplus to deficit units. Second approach is called 'the production approach' which views banks as producers who use labor and capital as inputs and deposits and loans as outputs. In this study we will follow the production approach. The production approach is followed by many such as in recent study for (Sathye, 2001; Neal, 2004).

In DEA the most efficient DMU's are identified by DEA efficiency equal to one. Any DMU with efficiency less than one would be considered relatively inefficient; which denotes the existence of banks having greater efficiency within the data set of banks analyzed. Using DEA will let us determine the amount of excess inputs utilized by each inefficient bank and determine by how much the outputs need to be increased without any change in the number of inputs. In other words, a more efficient bank would achieve the same amount of outputs using less amount of inputs, or it achieve the same level of output using less amount of inputs.

The DEA model is applied to 40 private and foreign banks for the period 2002-2009 using secondary data from databank, Lebanon Reserve Bank, the Association of Banks in Lebanon and the annual reports issued by banks. The banks included in the sample are listed by assets size in Table 3 . Banks will be split into groups using two methods. First method is according to assets size and second method is whether the bank is local or foreign.

The input oriented DEA technique is applied to the unbalanced data (292 observations). The data is unbalanced due to missing data for some banks.

Table 3: Banks by assets size

\begin{tabular}{|c|c|c|c|}
\hline Bank category & Name of Bank & Abbreviation used & Asset size \\
\hline \multirow[t]{15}{*}{ Small } & Rafidain Bank (2006) & RBA & $16.5^{* * *}$ \\
\hline & Habib Bank Limited & HBA & $28.6^{*}$ \\
\hline & Banque Lati Sal (2008) & BLA & $83.6 * *$ \\
\hline & Banca di Roma Spa (2006) & BDR & $83.7^{* * *}$ \\
\hline & The Saudi National Commercial Bank & SNCB & $110.5^{*}$ \\
\hline & Near East Commercial Bank Sal (2006) & NECB & $144.4^{* * *}$ \\
\hline & Standard Chartered Bank Sal & SCB & $145.9 *$ \\
\hline & Banque Pharaon and Chiha Sal (2008) & BPC & $176.5^{* *}$ \\
\hline & Finance Bank Sal & FBA & $240.4^{*}$ \\
\hline & Citibank NA & CBA & $241.8^{*}$ \\
\hline & Banque de l'habitat Sal (2006) & BHA & $245.8 * * *$ \\
\hline & National Bank of Kuwait (Lebanon) Sal & NBK & $261.2^{*}$ \\
\hline & Federal Bank of Lebanon Sal & FBL & $311.7^{*}$ \\
\hline & Jammal Trust Bank Sal & JTB & $401.3^{*}$ \\
\hline & The Syrian Lebanese Commercial Bank Sal & SLCB & $480.6^{*}$ \\
\hline \multirow[t]{8}{*}{ Medium } & Banque de l'industrie et du Travail Sal & BIT & $504.2^{*}$ \\
\hline & Middle-East and Africa Bank Sal & MEAB & $514.9 *$ \\
\hline & Société Nouvelle de la Banque de Syrie et du Liban & SNBS & $608.5^{*}$ \\
\hline & Banque Misr Liban Sal & BML & $620.5^{*}$ \\
\hline & Lebanese-Swiss Bank Sal & LSB & $624.8^{*}$ \\
\hline & Banque de Crédit National Sal (2006) & $\mathrm{BCN}$ & $710.4^{* * *}$ \\
\hline & HSBC Bank Middle East & HSBC & $815.8^{*}$ \\
\hline & Banque Nationale de Paris Intercontinentale & BNP & $964.8^{*}$ \\
\hline \multirow[t]{17}{*}{ Large } & Bank of Kuwait and the Arab World Sal & BKAW & $1037.9 *$ \\
\hline & Banque Européenne pour le Moyen Orient Sal & BEMO & $1191.2^{*}$ \\
\hline & Lebanon and Gulf Bank Sal & LGB & $1600.4^{*}$ \\
\hline & First National Bank Sal & FNB & $1730.1^{*}$ \\
\hline & Bank Lebanon for Commerce Bank Sal & BLC & $2015.8^{*}$ \\
\hline & Société Générale de Banque au Liban Sal & SGBL & $3581.6^{*}$ \\
\hline & Bank Beirut and Arab Countries Sal & BBAC & $3621.8^{*}$ \\
\hline & Lebanese-Canadian Bank Sal & LCB & $4618.7 *$ \\
\hline & Credit Libanais Sal & CLB & $4687.4^{*}$ \\
\hline & Bank of Beirut Sal & ВОВ & $6966.5^{*}$ \\
\hline & Banque Libano-Française Sal & BLF & $7475.0^{*}$ \\
\hline & BankMed Sal & MED & $10585.0 *$ \\
\hline & Fransabank Sal & FRB & $10812.6^{*}$ \\
\hline & Byblos Bank Sal & BBK & $13577.0 *$ \\
\hline & Banque du Liban et d'Outre-Mer Bank Sal & BLOM & $20702.4 *$ \\
\hline & Intercontinental Bank of Lebanon Sal & IBL & $23012.5^{*}$ \\
\hline & Bank Audi Sal - Audi Saradar Group & AUDI & $26486.0 *$ \\
\hline
\end{tabular}

Note: * denotes numbers from 2009, ** 2008 and *** 2006 (all numbers are expressed in billion US\$). Source: Banks’ balance sheets 
Since the efficient frontier is made up of best practice observations from the whole sample, we have formed the frontier from each set of cross-sectional data at a single time period.

In order to understand how the efficiency levels compare across the three groups of banks and how pure technical and scale efficiencies contribute to changes in technical efficiency, we will calculate the estimates of technical efficiency for each group and their growth rates for two sub-periods 2002-2006 and 2006-2009. The growth rates of technical efficiency are expressed as the sum of the growth rates of pure technical efficiency and scale efficiencies. That is:

$$
\begin{aligned}
\ln \left(\mathrm{TE}_{\mathrm{CRS}(\mathrm{t})} / \mathrm{TE}_{\mathrm{CRS}(\mathrm{t}-1)}\right)= & \ln \left(\mathrm{TE}_{\mathrm{VRS}(\mathrm{t})} / \mathrm{TE}_{\mathrm{VRS}(\mathrm{t}-1)}\right) \\
& +\ln \left(\mathrm{SE}_{(\mathrm{t})} / \ln \mathrm{SE}_{(\mathrm{t}-1)}\right)
\end{aligned}
$$

Following Eq. 4, the growth rates of technical efficiency are expressed as the sum of the growth rates of pure technical and scale efficiencies. Growth rates are calculated in two steps: first step we find the geometric mean for technical efficiency, pure technical efficiency and scale efficiency for each bank and then the change in geometric mean each year using the Ln Eq. 11. Last step is to find the average for the two subperiods, 2002-2006 and 2006-2009.

\section{RESULTS}

The results in Table 4 demonstrate the average annual growth rates of efficiencies according to banks' size. Results show that technical efficiency is the lowest among small banks during the two sub-periods 20022006 and 2006-2009 due to problems in scale efficiency. In general, technical efficiency has increased in all banks categories after the financial crisis due to substantial increase in pure technical efficiency in large and small banks and increase in scale efficiency for medium and small banks. During 2006-2009, large banks have outperformed both small and medium banks in terms of technical and pure technical efficiency improvements.

Table 5 reveals the average annual growth rates of efficiencies where banks are classified into local and foreign banks. It's clear from the results that local banks outperformed foreign banks in technical efficiency due to considerable increase in scale efficiency for local banks. Foreign banks has a major problem in scale efficiency but were better in management efficiency. After financial crisis technical efficiency has decreased in foreign banks which reflect
Table 4: Average annual growth rates of efficiency (in percentage)

\begin{tabular}{lccc}
\hline Period & $\begin{array}{l}\text { Growth rate } \\
\text { of TE }\end{array}$ & $\begin{array}{l}\text { Growth rate } \\
\text { of PTE }\end{array}$ & $\begin{array}{l}\text { Growth rate } \\
\text { of SE }\end{array}$ \\
\hline $\begin{array}{l}\text { Large Banks } \\
\text { 2002-2006 }\end{array}$ & -0.717 & -0.822 & 0.105 \\
2006-2009 & 2.093 & 2.484 & -0.391 \\
Medium Banks & & & \\
2002-2006 & -2.689 & 0.824 & -3.513 \\
2006-2009 & 1.787 & -3.316 & 5.103 \\
Small Banks & & & \\
2002-2006 & -0.450 & 0.453 & -0.903 \\
2006-2009 & 1.494 & 0.469 & 1.025 \\
All Banks & & & \\
2002-2006 & -1.051 & -0.061 & -0.990 \\
2006-2009 & 2.281 & 0.809 & 1.472 \\
\hline
\end{tabular}

Source: Authors' calculations

Table 5: Average annual growth rates of efficiency (in percentage)

\begin{tabular}{llll}
\hline Period & $\begin{array}{l}\text { Growth rate } \\
\text { of TE }\end{array}$ & $\begin{array}{l}\text { Growth rate } \\
\text { of PTE }\end{array}$ & $\begin{array}{l}\text { Growth rate } \\
\text { of SE }\end{array}$ \\
\hline Forgien Banks & & & \\
$002-2006$ & -3.315 & -1.699 & -1.616 \\
2006-2009 & -0.608 & -0.798 & 0.190 \\
Local Banks & & & -0.760 \\
2002-2006 & -0.280 & 0.481 & 1.486 \\
\hline 2006-2009 & 2.346 & 0.861 &
\end{tabular}

Source: Authors' calculations

the negative impact of the financial crisis on foreign banks; while local banks had a significant increase in technical efficiency caused by a considerable boost in scale efficiency.

Among the large banks, BBAC, BLF and IBL are found to be fully technically efficient and operating at the Most Productive Scale Size (MPSS) for 2008 and 2009. As for the medium sized banks, BNP and HSBC seem to be the most technical efficient and the most productive when compared to other medium banks within the sample period. Among the small sized banks, Citibank is fully efficient and productive during all the years, except in 2002. RBA and SLCB are efficient in 2002, FBL is efficient in 2008 and 2009 and BHA is efficient in 2002 and 2003 (Table 6).

\section{DISCUSSION}

Although there have been previous studies measuring the efficiency of the Lebanese banking sector, this study is the first of kind that investigates the Lebanese banking sector efficiency before and after the 2007 financial crisis. Although from previous section, it is clear that efficiency increased after the 2007 financial crisis in small banks, yet small banks remained suffering from low efficiency. The only possible solution for small banks to increase efficiency is through mergers; as continuous low efficiency can be considered as a warning signal that banks are at risk. 
J. Social Sci., 7 (2): 199-208, 2011

Table 6: Estimates of returns to scale, 2002-2009

\begin{tabular}{|c|c|c|c|c|c|c|c|c|}
\hline & 2009 & 2008 & 2007 & 2006 & 2005 & 2004 & 2003 & 2002 \\
\hline$\overline{\mathrm{BLC}}$ & DRS & DRS & DRS & DRS & IRS & MPSS & IRS & IRS \\
\hline BDR & & & & IRS & IRS & IRS & IRS & \\
\hline AUDI & DRS & DRS & DRS & DRS & DRS & DRS & MPSS & MPSS \\
\hline ВОВ & DRS & DRS & DRS & MPSS & IRS & IRS & IRS & IRS \\
\hline BKAW & IRS & IRS & IRS & IRS & IRS & MPSS & MPSS & MPSS \\
\hline MED & DRS & DRS & DRS & DRS & DRS & DRS & DRS & DRS \\
\hline BCN & & & & IRS & IRS & IRS & IRS & MPSS \\
\hline BHA & & & & IRS & DRS & DRS & MPSS & MPSS \\
\hline BIT & IRS & IRS & IRS & IRS & IRS & IRS & IRS & IRS \\
\hline BLA & & & & IRS & IRS & IRS & IRS & IRS \\
\hline BLF & MPSS & MPSS & MPSS & DRS & DRS & DRS & DRS & MPSS \\
\hline BML & IRS & IRS & IRS & & & & & \\
\hline BNP & & & & MPSS & MPSS & MPSS & MPSS & MPSS \\
\hline BPC & & & & IRS & IRS & IRS & IRS & IRS \\
\hline BBAC & MPSS & MPSS & IRS & IRS & IRS & IRS & IRS & MPSS \\
\hline BEMO & IRS & DRS & DRS & DRS & IRS & MPSS & MPSS & MPSS \\
\hline BLOM & DRS & DRS & DRS & DRS & DRS & MPSS & DRS & DRS \\
\hline BYBLOS & DRS & DRS & DRS & DRS & DRS & DRS & DRS & DRS \\
\hline CITI & MPSS & MPSS & MPSS & MPSS & MPSS & MPSS & MPSS & IRS \\
\hline CLB & DRS & DRS & DRS & DRS & DRS & DRS & DRS & DRS \\
\hline CBK & DRS & DRS & DRS & DRS & DRS & DRS & DRS & DRS \\
\hline FBL & MPSS & MPSS & IRS & IRS & IRS & IRS & IRS & IRS \\
\hline FBA & IRS & IRS & IRS & IRS & IRS & IRS & IRS & IRS \\
\hline FNB & IRS & IRS & IRS & IRS & IRS & IRS & IRS & IRS \\
\hline FRB & DRS & DRS & DRS & DRS & DRS & DRS & DRS & DRS \\
\hline HBA & IRS & IRS & IRS & IRS & IRS & IRS & & \\
\hline HSBC & MPSS & MPSS & MPSS & IRS & MPSS & IRS & IRS & MPSS \\
\hline IBL & MPSS & MPSS & MPSS & DRS & MPSS & MPSS & IRS & IRS \\
\hline JTB & IRS & IRS & IRS & IRS & IRS & IRS & IRS & IRS \\
\hline LCB & IRS & IRS & MPSS & DRS & DRS & DRS & DRS & IRS \\
\hline LSB & IRS & IRS & IRS & IRS & IRS & IRS & IRS & IRS \\
\hline LGB & IRS & DRS & DRS & MPSS & MPSS & DRS & MPSS & DRS \\
\hline MEAB & IRS & IRS & IRS & IRS & IRS & IRS & & IRS \\
\hline NBK & IRS & IRS & IRS & IRS & IRS & IRS & IRS & IRS \\
\hline NECB & & & & IRS & IRS & IRS & IRS & IRS \\
\hline RBA & & & & IRS & & IRS & IRS & MPSS \\
\hline SGBL & DRS & DRS & DRS & DRS & DRS & DRS & DRS & MPSS \\
\hline SNBS & IRS & IRS & IRS & IRS & IRS & IRS & & \\
\hline SCB & IRS & IRS & IRS & IRS & IRS & IRS & IRS & IRS \\
\hline SNCB & IRS & IRS & IRS & IRS & IRS & IRS & IRS & IRS \\
\hline SLCB & IRS & IRS & IRS & IRS & IRS & IRS & IRS & MPSS \\
\hline
\end{tabular}

Note: MPSS refers to that size of operations where a firm's production of outputs is maximized per unit of inputs, DRS refers to decreasing returns to scale and IRS refers to increasing returns to scale. Source: Authors' calculations

Most important results relate to the behavior of scale efficiency. In 2009, scale efficiency has increased which can be attributed to the efforts made by medium sized banks to open new branches. As for large banks, scale efficiency has decreased between 2006 and 2009 when compared to the period between 2002 and 2006 due to decreasing scale efficiency. This means that large banks are very large and they should become smaller (this means that for every $\$ 1$ they spend, they make less than $\$ 1$ back). This can be attributed to the re-structuring efforts by large sized banks to increase use in internet and electronic banking without closing branches and shedding staff numbers. As such, they had greater efficiency level by taking advantage of electronic bank services but they had relatively very slow reaction decreasing number of branches. As for small banks, they had experienced an increase in scale efficiency but still suffered from low scale efficiency when compared to medium and large and medium banks. While medium banks experienced increase in scale efficiency, they have struggled at management level which leads a decrease in pure technical efficiency.

\section{CONCLUSION}

This study has examined technical efficiency of 40 banks operating in Lebanon during two sub-periods 2002-2006 and 2006-2009. The DEA production approach is applied where deposits and loans are considered as outputs and labor and capital are 
considered as inputs. Technical efficiency is cut down to pure technical efficiency and scale efficiency. This study tried to shed some light on whether banks are working at full efficiency or non-optimal scales. The empirical results showed that efficiency have increased in all three categories (small, medium and large banks) after the financial crisis. Another interesting result is that Citibank, HSBC, BBAC, IBL and FBL are working at full efficiency, while RBA, HBA, BCN, SGBL, BLA and SLCB are found to be prominently inefficient. Although technical efficiency has increased rapidly in small sized banks, technical efficiency is the lowest among small banks. The medium sized banks experienced a huge increase in scale efficiency but struggled with pure technical efficiency. As for large banks, although they have experienced a decrease in scale efficiency, yet they are considered the most efficient in technical efficiency, scale efficiency and pure technical efficiency. Most of small and medium banks are operating at increasing returns to scale, while most of the large banks are operating at decreasing returns to scale. As small and medium banks are found to be working at increasing returns to scale, greater benefits might arise from encouraging consolidation between them.

\section{REFERENCES}

Al-Faraj, T. N., A.S. Alidi and K.A. Bu-Bshait, 1993. Evaluation of bank branches by means of data envelopment analysis. Int. J. Operat. Prod. Manage., $\quad$ 13: $\quad 45-52 . \quad$ DOI: 10.1108/01443579310043628

Al-Shammari, M. and A. Salimi, 1998. Modeling the operating efficiency of banks: A nonparametric methodology. Logist. Info. Manage., 11: 5-17. DOI: 10.1108/09576059810202196

Athanassopoulos, A.D. and S.P. Curram, 1996. A comparison of data envelopment analysis and artificial neural networks as tools for assessing the efficiency of decision making units. J. Operat. Res. Soc., 47: 1000-1016. DOI: 10.2307/3010408

Coelli, T., D.S.P. Rao and G.E. Battase, 1998. An Introduction to Efficiency and Productivity Analysis. 2nd Edn., Springer, ISBN: 9780387242668, pp: 350

Debreu, G., 1951. The coefficient of resource utilization. Econometrica, 19: 273-292. DOI: $10.2307 / 1906814$

Emrouznejad, A. and A.L. Anouze, 2009. A note on the modeling the efficiency of top Arab banks. Expert Sys. Appl., 36: 5741-5744. DOI: 10.1016/j.eswa.2008.06.075
Fare, R. and C.A.K. Lovell, 1978. Measuring the technical efficiency of production. J. Econ. Theory, 19: 150-162. DOI: 10.1016/00220531(78)90060-1

Farrell, M., 1957. The measurement of productive efficiency. J. Royal Stat. Soc., 120: 253-290. DOI: $10.2307 / 2343100$

Favero, C.A. and L. Papi, 1995. Technical efficiency and scale efficiency in the italian banking sector: A non-parametric approach. Applied Econ., 27: 385395. DOI: $10.1080 / 00036849500000123$

Giokas, D., 1991. Bank branch operating efficiency: A comparative application of DEA and the loglinear model. Omega, 19: 549-557. DOI: 10.1016/0305-0483(91)90005-E

Golany, B. and J.E. Storbeck, 1999. A data envelopment analysis of the operational efficiency of bank branches. Interfaces, 29: 1426. DOI: $10.1287 /$ inte.29.3.14

Hassan, M.K., A. Al-Sharkas and A. Samad, 2004. An empirical study of relative efficiency of the banking industry in Bahrain. Stud. Econ. Finance, 22: 40-69. DOI: 10.1108/eb028779

Mostafa, M., 2007. Modeling the efficiency of top Arab banks: A DEA-neural network approach. Expert Syst. Appl., 36: 309-320. DOI: 10.1016/j.eswa.2007.09.001

Neal, P., 2004. X-efficiency and productivity change in Australian banking. Australian Econ., 43: 174-91. DOI: 10.1111/j.1467-8454.2004.00223.x

Oral, M. and R. Yolalan, 1990. An empirical study on measuring operating efficiency and profitability of bank branches. Eur. J. Operat. Res., 46: 282-294. DOI: 10.1016/0377-2217(90)90002-S

Parkan, C., 1987. Measuring the efficiency of service operations: An application to bank branches. Eng. Costs Product. Econ., 12: 237-242. DOI: 10.1016/0167-188X(87)90083-8

Resti, A., 1997. Evaluating the cost efficiency of the Italian banking system: What can be learned from the joint application of parametric and nonparametric techniques. J. Bank. Finance, 21: 221-250. DOI: 10.1016/S0378-4266(96)00036-2

Saad, W. and C. El-Moussawi, 2008. Efficiency and productivity growth of the Arab commercial banking sector: A non-parametric approach. J. Dev. Econ. Policies, 10: 7-35.

Saad, W. and C. El-Moussawi, 2009. Evaluating the productive efficiency of Lebanese commercial banks: Parametric and non-parametric approaches. Int. Manage. Rev., 5: 5-19. 
Sathye, M., 2001. X-efficiency in Australian banking: An empirical investigation. J. Bank. Finance, 25: 613-630. DOI: 10.1016/S0378-4266(00)00156-4

Schaffnit, C., D. Rosen and J.C. Paradi, 1997. Best practice analysis of bank branches: An application of DEA in a large Canadian bank. Eur. J. Operat. Res., 98: 269-289. DOI: 10.1016/S03772217(96)00347-5

Seiford, L.M. and J. Zhu, 1999. Profitability and marketability of the top 55 U.S. commercial banks. Manage. Sci., 45: 1270-1288. DOI: 10.1287/mnsc.45.9.1270

Sherman, D. and F. Gold, 1985. Bank Branch operating efficiency: Evaluation with data envelopment analysis. J. Bank and Finance, 9: 297-315. DOI: 10.1016/0378-4266(85)90025-1
Sherman, H.D. and G. Ladino, 1995. Managing bank productivity using Data Envelopment Analysis (DEA). Interfaces, 25: 60-73. DOI: 10.1287/inte.25.2.60

Vassiloglou, N. and D. Giokas, 1990. A study of the relative efficiency of bank branches: An application of data envelopment analysis. J. Operat. Res. Soc., 41: 591-597. DOI: 10.2307/2583436

Wu, D., Z. Yang and L. Liang, 2006. Using DEAneural network approach to evaluate branch efficiency of a large Canadian bank. Expert Syst. Appl., 31: 108-115. DOI: 10.1016/j.eswa.2005.09.034 